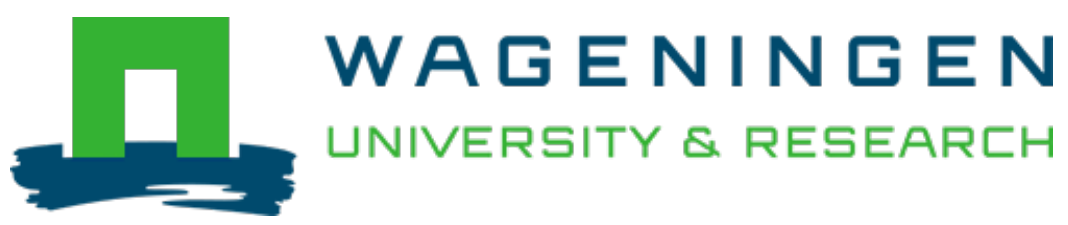

\title{
Acetotrophic sulfate-reducing consortia develop active biofilms on zeolite and glass beads in batch cultures at initial $\mathrm{pH} 3$
}

\author{
Applied Microbiology and Biotechnology \\ Campos-Quevedo, Nohemi; Moreno-Perlin, Tonatiuh; Razo-Flores, Elías; Stams, Alfons J.M.; Celis, Lourdes \\ B. et al \\ https://doi.org/10.1007/s00253-021-11365-0
}

This article is made publicly available in the institutional repository of Wageningen University and Research, under the terms of article $25 \mathrm{fa}$ of the Dutch Copyright Act, also known as the Amendment Taverne. This has been done with explicit consent by the author.

Article 25 fa states that the author of a short scientific work funded either wholly or partially by Dutch public funds is entitled to make that work publicly available for no consideration following a reasonable period of time after the work was first published, provided that clear reference is made to the source of the first publication of the work.

This publication is distributed under The Association of Universities in the Netherlands (VSNU) 'Article 25fa implementation' project. In this project research outputs of researchers employed by Dutch Universities that comply with the legal requirements of Article $25 \mathrm{fa}$ of the Dutch Copyright Act are distributed online and free of cost or other barriers in institutional repositories. Research outputs are distributed six months after their first online publication in the original published version and with proper attribution to the source of the original publication.

You are permitted to download and use the publication for personal purposes. All rights remain with the author(s) and / or copyright owner(s) of this work. Any use of the publication or parts of it other than authorised under article $25 \mathrm{fa}$ of the Dutch Copyright act is prohibited. Wageningen University \& Research and the author(s) of this publication shall not be held responsible or liable for any damages resulting from your (re)use of this publication.

For questions regarding the public availability of this article please contact openscience.library@,wur.nl 


\title{
Acetotrophic sulfate-reducing consortia develop active biofilms on zeolite and glass beads in batch cultures at initial $\mathrm{pH} 3$
}

\author{
Nohemi Campos-Quevedo ${ }^{1,2}$ - Tonatiuh Moreno-Perlin ${ }^{1}$ (1) - Elías Razo-Flores ${ }^{1}$ • Alfons J.M. Stams ${ }^{2,3}$ • \\ Lourdes B. Celis ${ }^{1}$ (D) - Irene Sánchez-Andrea ${ }^{2}$
}

Received: 11 December 2020 / Revised: 13 May 2021 / Accepted: 25 May 2021 / Published online: 14 June 2021

(C) The Author(s), under exclusive licence to Springer-Verlag GmbH Germany, part of Springer Nature 2021

\begin{abstract}
Sulfate-reducing microbial communities remain a suitable option for the remediation of acid mine drainage using several types of carrier materials and appropriate reactor configurations. However, acetate prevails as a product derived from the incomplete oxidation of most organic substrates by sulfate reducers, limiting the efficiency of the whole process. An established sulfatereducing consortium, able to degrade acetate at initial acidic $\mathrm{pH}$ (3.0), was used to develop biofilms over granular activated carbon (GAC), glass beads, and zeolite as carrier materials. In batch assays using glycerol, biofilms successfully formed on zeolite, glass beads, and GAC with sulfide production rates of $0.32,0.26$, and $0.14 \mathrm{mmol} \mathrm{H} \mathrm{H}_{2} \mathrm{~S} / \mathrm{L} \cdot \mathrm{d}$, respectively, but only with glass beads and zeolite, acetate was degraded completely. The planktonic and biofilm communities were determined by the $16 \mathrm{~S}$ rRNA gene analysis to evaluate the microbial selectivity of the carrier materials. In total, 46 OTUs (family level) composed the microbial communities. Ruminococcaceae and Clostridiaceae families were present in zeolite and glass beads, whereas Peptococcaceae was mostly enriched on zeolite and Desulfovibrionaceae on glass beads. The most abundant sulfate reducer in the biofilm of zeolite was Desulfotomaculum sp., while Desulfatirhabdium sp. abounded in the planktonic community. With glass beads, Desulfovibrio sp. dominated the biofilm and the planktonic communities. Our results indicate that both materials (glass beads and zeolite) selected different key sulfate-reducing microorganisms able to oxidize glycerol completely at initial acidic $\mathrm{pH}$, which is relevant for a future application of the consortium in continuous bioreactors to treat acidic streams.
\end{abstract}

\section{Key points}

- Complete consumption of glycerol and acetate at acidic pH by sulfate reduction.

- Glass beads and zeolite are suitable materials to form sulfate-reducing biofilms.

- Acetotrophic sulfate-reducing bacteria attached to zeolite preferably.

Keywords Acidic $\mathrm{pH} \cdot$ Acidophilic consortium $\cdot$ Acetate biodegradation $\cdot$ Glass beads $\cdot$ Sulfate reduction $\cdot$ Zeolite

Lourdes B. Celis

celis@ ipicyt.edu.mx

Irene Sánchez-Andrea

irene.sanchezandrea@wur.nl

1 División de Ciencias Ambientales, Instituto Potosino de Investigación Científica y Tecnológica, Camino a la Presa San José 2055, Lomas 4a. Sección, C.P. 78216, San Luis Potosí, S.L.P., México

2 Laboratory of Microbiology, Wageningen University \& Research, Stippeneng 4, 6708 WE Wageningen, The Netherlands

3 Institute for Biotechnology and Bioengineering, Centre of Biological Engineering, University of Minho, Campus de Gualtar, 4710-057 Braga, Portugal

\section{Introduction}

In the last 20 years, biological sulfate reduction has attracted attention for the remediation of effluents that contain metals. Sulfate reduction offers several advantages when compared to other remediation options such as chemical precipitation, making possible the recovery of metals as metal sulfides. Sulfate-reducing microorganisms (SRM) couple the reduction of sulfate $\left(\mathrm{SO}_{4}{ }^{2-}\right)$ to sulfide $\left(\mathrm{H}_{2} \mathrm{~S} / \mathrm{HS}^{-}\right)$with the oxidation of hydrogen and low molecular weight organic substrates such as lactate, propionate, or butyrate, among others (Kaksonen and Puhakka 2007). Sulfide reacts with metal divalent anions forming metal sulfides that precipitate due to their low 
solubility (Sánchez-Andrea et al. 2014). A wide variety of reactor types can be used to treat metal-containing acidic streams by sulfate reduction (Sahinkaya et al. 2011; Habe et al. 2020). High-rate reactors with biomass retention offer the advantage of forming the metal sulfides in one step, such as the fluidized bed reactors (Papirio et al. 2013), fixed bed reactors (El Bayoumy et al. 1999), and continuous flow reactor with biomass retention (Nancucheo and Johnson 2012).

A drawback for implementing sulfate reduction for the treatment of acidic metal-containing streams at full scale is the typical acidic nature of such effluents (Ayangbenro et al. 2018). Most known SRM are neutrophiles that are negatively affected by low $\mathrm{pH}(<5)$ (Kaksonen and Puhakka 2007). Also, the efficiency to produce sulfide is limited, as not all SRM degrade the substrate completely to $\mathrm{CO}_{2}$, usually leaving acetate as a product (Kleikemper et al. 2002). For the efficient treatment by sulfate reduction of acidic effluents that contain metals, it is desirable to use SRM communities that can oxidize the substrate completely at acidic $\mathrm{pH}(<5)$ (SánchezAndrea et al. 2014); otherwise the produced acetate may cause toxicity (Koschorreck et al. 2002). Also, since several reactor configurations for the treatment of acid streams rely on biomass retention, the sulfate-reducing community should be able to attach to the carrier material and form a biofilm (Sánchez-Andrea et al. 2014). Several types of carrier materials have been used to form sulfate-reducing biofilms; for instance, glass beads have been used in percolating columns to evaluate the tolerance to acid stress $(\mathrm{pH} 2.5-4.0)$ and to determine the sulfate reduction efficiency with different combinations of carbon sources (glycerol, lactate, and ethanol) using enrichments of acidophilic and neutrophilic SRM (Kolmert and Johnson 2001). In continuous biofilm reactors, glass beads also served as carrier material of SRM to remove sulfate from extremely acidic synthetic groundwater $(\mathrm{pH} 1.6-$ 3.0) using glycerol as the substrate (Nancucheo and Johnson 2014). Nevertheless, acetate remained as the end product, but it was reported that after lowering the $\mathrm{pH}$ of the reactor from 4.5 to 3.0, the acetate concentration in the effluent decreased. Granular activated carbon (GAC) is another carrier material used to form biofilms of SRM at acidic $\mathrm{pH}(\mathrm{pH} 5)$ that helped to increase the accumulation and retention of biomass, achieving sulfate removal efficiencies up to $82 \%$ and sulfate removal rates of $340 \mathrm{mg} \mathrm{SO}{ }_{4}^{2-} / \mathrm{L} \cdot \mathrm{d}$ in UASB reactors (SánchezAndrea et al. 2012). Sahinkaya et al. (2011) used activated carbon in fluidized reactors fed with real acid mine drainage and ethanol as the substrate, at initial $\mathrm{pH}$ of 2.7, but the substrate was incompletely degraded to acetate. Similarly, silicate minerals helped to develop sulfate-reducing biofilms and treat acidic synthetic water $(\mathrm{pH} 2.5-5.2)$ with lactate and ethanol as the substrates (Kaksonen et al. 2006). In this case, acetate oxidation was the rate-limiting step even when the $\mathrm{pH}$ of the reactor, which was not controlled, reached values from 6.8 to 7.9. Other carrier materials used to develop sulfate-reducing biofilms include polyurethane foam (Silva et al. 2006; Rodriguez-Freire et al. 2016), porous scouring pads and sand particles (Baskaran and Nemati 2006), alumina (Silva et al. 2006), zeolite (Kim et al. 2015), and pozzolana (BattagliaBrunet et al. 2012).

Despite the clear advances in the treatment of acidic and metal-containing effluents by sulfate reduction in biofilm reactors, there is a lack of information on the composition of the communities prevailing in the biofilms and the liquid phase (planktonic community), particularly in the early stages of biofilm formation. In addition, just a few studies analyzed the microbial communities developed in the carrier material at stress conditions, such as acidic $\mathrm{pH}$, reporting sulfate reducers, and fermenting bacteria as the main guilds composing the communities (Baskaran and Nemati 2006; Montoya et al. 2013). In this work, the performance of sulfate-reducing biofilms at acidic conditions (initial $\mathrm{pH} 3$ ) using three different carrier materials (i.e., porous glass beads, zeolite, and granular activated carbon) was evaluated with the aim of obtaining biofilms able to oxidize completely the substrate (acetate oxidation) and characterize them. The microbial composition during biofilm development of the attached and planktonic communities was studied by Illumina HiSeq analysis of PCR-amplified 16S rRNA gene products. The results showed complete acetate oxidation at initial $\mathrm{pH} 3$ only with zeolite and glass beads, probably by Desulfotomaculum and Desulfatirhabdium, and microbial community selectivity depending on the carrier used.

\section{Materials and methods}

\section{Mineral basal medium}

The mineral basal medium used in all the experiments contained (mM): $50 \mathrm{NH}_{4} \mathrm{Cl}, 30 \mathrm{NaCl}, 40 \mathrm{MgCl}_{2} \cdot 6 \mathrm{H}_{2} \mathrm{O}, 75$ $\mathrm{CaCl}_{2} \cdot \mathrm{H}_{2} \mathrm{O}, 1 \mathrm{~mL} / \mathrm{L}$ trace element solution $(50 \mathrm{mM} \mathrm{HCl}$, $1 \mathrm{mM} \mathrm{H}_{3} \mathrm{BO}_{3}, 0.5 \mathrm{mM} \mathrm{MnCl}, 7.5 \mathrm{mM} \mathrm{FeCl}_{2}, 0.5 \mathrm{mM}$ $\mathrm{CoCl}_{2}, 0.1 \mathrm{mM} \mathrm{NiCl} 2$, and $0.5 \mathrm{mM} \mathrm{ZnCl}_{2}$ ), and $0.1 \mathrm{~g} / \mathrm{L}$ of yeast extract (modified from Stams et al. 1993). The medium was supplemented with $10 \mathrm{mM} \mathrm{Na}_{2} \mathrm{SO}_{4}$ as the electron acceptor, and the stoichiometric concentration of glycerol (electron donor) is $5.71 \mathrm{mM}$. The $\mathrm{pH}$ was adjusted to 3 using $1 \mathrm{~N} \mathrm{HCl}$ before autoclaving.

\section{Carrier materials}

Three different carrier materials, glass beads, granular activated carbon (GAC), and zeolite, were used to develop the sulfate-reducing biofilms (for details, see Table S1). Before use, each material was washed several times with deionized water until the rinse liquid was clear; then, the materials were dried at $105^{\circ} \mathrm{C}$ for $4 \mathrm{~h}$. Each carrier was left overnight in a 
serum bottle containing mineral basal medium ( $\mathrm{pH} 2.5$, without glycerol, sulfate, and yeast extract) under continuous stirring (100 rpm). Subsequently, the medium was discarded, and fresh mineral basal medium was replenished to the bottle with the carrier material; this time the medium contained sulfate, glycerol, and yeast extract and adjusted to $\mathrm{pH} 3$. The bottle was autoclaved (20 min, $15 \mathrm{psi}$ ) and finally inoculated under anaerobic conditions $\left(\mathrm{N}_{2} / \mathrm{CO}_{2}, 80: 20 \%\right)$.

\section{Source of microorganisms}

The inoculum was an acid-tolerant sulfate-reducing consortium that degraded glycerol and acetate to $\mathrm{CO}_{2}$ at initial $\mathrm{pH}$ 3. The consortium used $75 \%$ of the substrate (glycerol) for sulfate reduction and formed microbial aggregates (CamposQuevedo et al. 2020). The sample to develop this consortium was originally retrieved from a contaminated sulfur mine in Mexico that was enriched for over 1 year by gradually reducing the pH from 6 to 4 (Moreno-Perlin et al. 2019).

\section{Experimental design}

For each carrier material, a total of 15 experimental units (serum bottles) were set up (Fig. S1). Three of the experimental units served to conduct the sulfate-reducing activity (triplicate assay); the other 12 experimental units were opened (sacrificed) at regular intervals to obtain DNA samples. Each bottle $(120 \mathrm{~mL})$ contained $40 \mathrm{~mL}$ of anaerobic medium, 15 $\mathrm{mL}$ of carrier material, and $20 \%(\mathrm{v} / \mathrm{v})$ of inoculum. Additionally, abiotic controls were set up, which only contained medium $(40 \mathrm{~mL})$ and the carrier material $(15 \mathrm{~mL})$, while the biological control for all the experiments only contained medium and inoculum. The headspace of all the bottles was flushed with $1.5 \mathrm{~atm}\left(\mathrm{~N}_{2} / \mathrm{CO}_{2} ; 80: 20 \%\right)$. Before adding the inoculum, all the bottles containing zeolite, glass beads, and granular activated carbon and the bottle of the biological control were sterilized $\left(120^{\circ} \mathrm{C}, 20 \mathrm{~min}\right)$. After inoculation, the bottles were incubated at $30^{\circ} \mathrm{C}$ in the dark and agitated $(75 \mathrm{rpm})$. Samples were taken from the triplicate and control assays to determine sulfate, sulfide, $\mathrm{pH}$, and volatile fatty acids at days $0,5,7,10,12,15,20,25$, and 30 . On the same days, one bottle (from the remaining 12 sacrifice bottles) was opened to obtain DNA from the carrier material and the liquid phase; all the DNA samples were stored at $-20{ }^{\circ} \mathrm{C}$. Before opening the bottle, samples were taken to determine sulfate, sulfide, $\mathrm{pH}$, and volatile fatty acids and make sure of the reproducibility compared to the triplicate assays. After finishing and analyzing the kinetic profiles of the triplicate assays, only those experiments that performed similarly to the biological control, that is, the experiments that achieved complete oxidation of the substrate, were selected for subsequent DNA analysis and SEM imaging; therefore, we discarded GAC for further processing.
To analyze the communities, from the stored DNA samples, we selected those corresponding to the consumption of glycerol and acetate. With zeolite, glycerol was consumed on day 7 and acetate on day 25 , whereas with glass beads, the consumption was on days 10 and 30, respectively. Only the DNA samples from zeolite and glass beads were analyzed by Illumina HiSeq sequencing because only in these two experiments the acetate was consumed completely.

\section{Physicochemical analyses}

Glycerol and its products (acetate, propionate, butyrate, ethanol, and 1,3 propanediol) were quantified using LKB highperformance liquid chromatography (Thermo Scientific SpectraSystem HPLC, Waltham, MA) fitted with a Varian Metacarb 67H $300 \mathrm{~mm}$ column (Varian, Walnut Creek, CA), using $\mathrm{H}_{2} \mathrm{SO}_{4}(0.01 \mathrm{~N})$ as eluent at a flow rate of 0.8 $\mathrm{mL} / \mathrm{min}$. Sulfide in the liquid phase was determined by the methylene blue spectrophotometric method (Broenkow and Cline 1969). Sulfate concentrations were quantified using a Dionex ICS-1000 ion chromatograph (Thermo Scientific, Waltham, MA). The $\mathrm{pH}$ was measured with a Thermo Scientific TM Orion TM VersaStar potentiometer.

\section{Scanning electron microscopy (SEM) analysis}

Samples of zeolite and glass beads were taken for SEM images when glycerol and acetate were depleted. Since the consumption occurred at different times, the samples for zeolite were taken at days 7 (glycerol consumption) and 25 (acetate consumption) and for glass beads at days 10 (glycerol consumption) and 30 (acetate consumption). Samples of the raw materials were also observed. The samples of zeolite and glass beads were fixed to poly-L-lysine $12 \mathrm{~mm}$ coated coverslips (Corning, BioCoat) and incubated for $5 \mathrm{~h}$ at room temperature. The biofilms attached to the carrier materials were fixed in $2.5 \%$ glutaraldehyde in $0.1 \mathrm{M}$ phosphate buffer (PBS) ( $\mathrm{pH}$ 7.4) for $2 \mathrm{~h}$ and then rinsed with $0.1 \mathrm{M}$ of PBS buffer and postfixed with $1 \%$ osmium tetroxide for $1 \mathrm{~h}$. The samples were then dehydrated with ethanol series $(10,30,50,70,80,96$, and $100 \%$ ) and dried to the critical point in 100\% ethanol in a Leica EM CPD300 system (Leica Microsystems); finally, the samples were mounted onto aluminum stubs and coated with tungsten.

\section{Community composition}

DNA was extracted from the zeolite and glass beads experiments, from both the liquid and solid phases, using the FastDNA SPIN Kit for Soil (Qbiogene, Carlsbad, CA), following the manufacturer's instructions. The samples were taken from the sacrifice bottles of zeolite at days 7 and 25 and from glass beads at days 10 and 30; these days corresponded 
to depletion of glycerol (day 7 or 10) and acetate (day 25 or $30)$. The DNA of the inoculum was also extracted. The DNA concentration and purity were checked with a NanoDrop spectrophotometer (NanoDrop Technologies, Wilmington, DE) and adjusted to a concentration between 10 and $20 \mathrm{ng} / \mu \mathrm{L}$ and used as the template for PCR amplification. PCR was performed in a final volume of $100 \mu \mathrm{l}$ containing $1 \mathrm{X}$ HF PCR buffer, $0.2 \mathrm{mM}$ dNTPs, $2 \mathrm{U} / \mu \mathrm{L}$ of Phusion Hot Start II DNA polymerase (Promega, Madison, WI), $10 \mu \mathrm{M}$ of forward and reverse primer mixture, $200 \mu \mathrm{M}$ of barcoded forward primer with titanium sequence adaptor, 338R-I+II (Biolegio BV, Nijmegen, The Netherlands), 0.1-0.6 ng/ $\mathrm{LL}$ of the template DNA, and nuclease-free water (to final volume). The PCR program was as follows: initial denaturation $\left(98^{\circ} \mathrm{C}, 30 \mathrm{~s}\right), 30$ cycles of denaturation $\left(98^{\circ} \mathrm{C}, 10 \mathrm{~s}\right)$, annealing $\left(54{ }^{\circ} \mathrm{C}, 30 \mathrm{~s}\right)$, extension $\left(72{ }^{\circ} \mathrm{C}, 30 \mathrm{~s}\right)$, and a final extension step $\left(72{ }^{\circ} \mathrm{C}\right.$ for $\left.10 \mathrm{~min}\right)$. The amplicons were visualized after gel electrophoresis in agarose $(1 \% \mathrm{w} / \mathrm{v})$ with $1 \mathrm{x}$ SYBR Safe (Invitrogen, Carlsbad, CA). The negative control (water) was amplified in parallel with no product.

The PCR products were purified (High Pure Cleanup Micro Kit, Roche, Basel, Switzerland) and pooled in equimolar amounts at a final DNA concentration of $200 \mathrm{ng} / \mu \mathrm{L}$. Highthroughput sequencing of the pooled amplicons was performed in an FLX Genome Sequencer combined with titanium chemistry (GATC-Biotech, Konstanz, Germany). 16S rRNA gene sequencing data was analyzed using NG-Tax (Ramiro-Garcia et al. 2016). This pipeline was used to demultiplex the reads by sample using the barcodes. Operational taxonomic units (OTUs) were defined using SILVA 16S rRNA gene reference database (Quast et al. 2013). For subsequent analysis, QIIME 2 (v.2.2019.1) was used.

Two mock communities Mock3 and Mock4, developed in the MolEco Laboratory of Wageningen University, were used as controls; the correlation coefficient between the reads of the standard and the analyzed mock communities was 0.18 for both (Mock 3 and Mock 4). The negative control (reactants with water) yielded only 173 reads representing $0.09 \%$ of the average of the total reads of all the samples $(\sim 190,000)$. We used the ecology package "vegan" (Oksanen et al. 2019) and $\mathrm{R}$ version 3.4.2 ( $\mathrm{R}$ Core Team and R Development Core Team. 2005) to calculate the distance among the samples and to obtain the richness, Shannon-Wiener index, and Simpson index of dominance and evenness. The sequences are deposited in the NCBI nucleotide sequence database GenBank under the BioProject accession number: PRJNA646005.

\section{Statistical analysis}

Non-metric multidimensional scaling (NMDS) and redundancy analysis (RDA) were done with Software R (version 3.4.2)
(R Core Team and R Development Core Team. 2005) and package "vegan" (Oksanen et al. 2019) using RStudio software (version 1.1.383; RStudio Inc., Boston, MA).

\section{Results}

\section{Sulfate-reducing activity profiles}

The assays performed in triplicate helped to monitor the kinetics of glycerol and sulfate consumption and the production of sulfide, acetate, propionate, and other by-products. In the assays with granular activated carbon (GAC) and zeolite, it was not possible to detect sulfide because these materials have functional groups that adsorbed sulfide. Therefore, the production of sulfide was calculated from the reduction of sulfate, taking into account the abiotic controls of each material (Figs. 1 and S2). In this way, the kinetic profiles of the sulfide production with zeolite and GAC were constructed. Zeolite and glass beads allowed the sulfate-reducing consortium to perform similarly to the biological control, in terms of sulfide production (Fig. 1) and glycerol and acetate consumption (Fig. 2). The results also show that the sulfate-reducing activity improved when using zeolite as carrier material. In the case of GAC, it was not possible to reproduce the performance of the consortium without support; moreover, acetate was not consumed within 30 days as in the original inoculum (biological control) (Figs. S2A and 2E).

In the majority of the assays, sulfate was gradually consumed, reaching a final concentration close to $3 \mathrm{mM}$ at day 30 and concentrations of sulfide between 6 and $7 \mathrm{mM}$ (Figs. 1 and S2), including the biological control without carrier (8.6 $\mathrm{mM}$ ) (Fig. 1E). Only in the assays with zeolite, there was no sulfate at day 30 , and the sulfide produced $(9 \mathrm{mM})$ was the highest (Fig. 1A). The assays with glass beads showed a sulfide concentration of $7.5 \mathrm{mM}$, whereas with GAC, the lowest sulfate reduction activity was attained $\left(<6 \mathrm{mM} \mathrm{H}_{2} \mathrm{~S}\right)$ (Figs. 1B and $\mathrm{S} 2 \mathrm{~B}$ ). In every experiment, the $\mathrm{pH}$ increased gradually to neutrality ( $c a .7$, Fig. 1 and S2B) because the $\mathrm{pH}$ was not controlled.

The main differences among the experiments are appreciated from the analysis of the substrate fate (Figs. 2 and S2). Glycerol was completely consumed within 7 to 10 days depending on the carrier material, being faster with zeolite (7 days) similar to the biological control (Fig. 2E), than with glass beads or GAC. Using zeolite or glass beads as carrier material, glycerol was first degraded to acetate and propionate. In the biological control and with glass beads, acetate was completely consumed by day 30 (Figs. 2E and B), while acetate was consumed earlier (day 25) in the zeolite experiments (Fig. 2A). The consumption of glycerol also yielded some propionate (1.5 $\mathrm{mM}$, day 7); with zeolite as carrier, that was consumed by day 10 . In the assay with glass beads, the 
Fig. 1 Kinetic profiles of sulfate consumption, sulfide production, and $\mathrm{pH}$ in the experiments with $\mathbf{A}$ zeolite (ZEO); $\mathbf{B}$ glass beads (GB); and $\mathbf{E}$ biological control (BIO) without carrier material. Profiles of sulfate and $\mathrm{pH}$ in the abiotic experiments with $\mathbf{C}$ zeolite $(\mathrm{ZEO} / \mathrm{C})$ and $\mathbf{D}$ glass beads $(\mathrm{GB} /$ C)
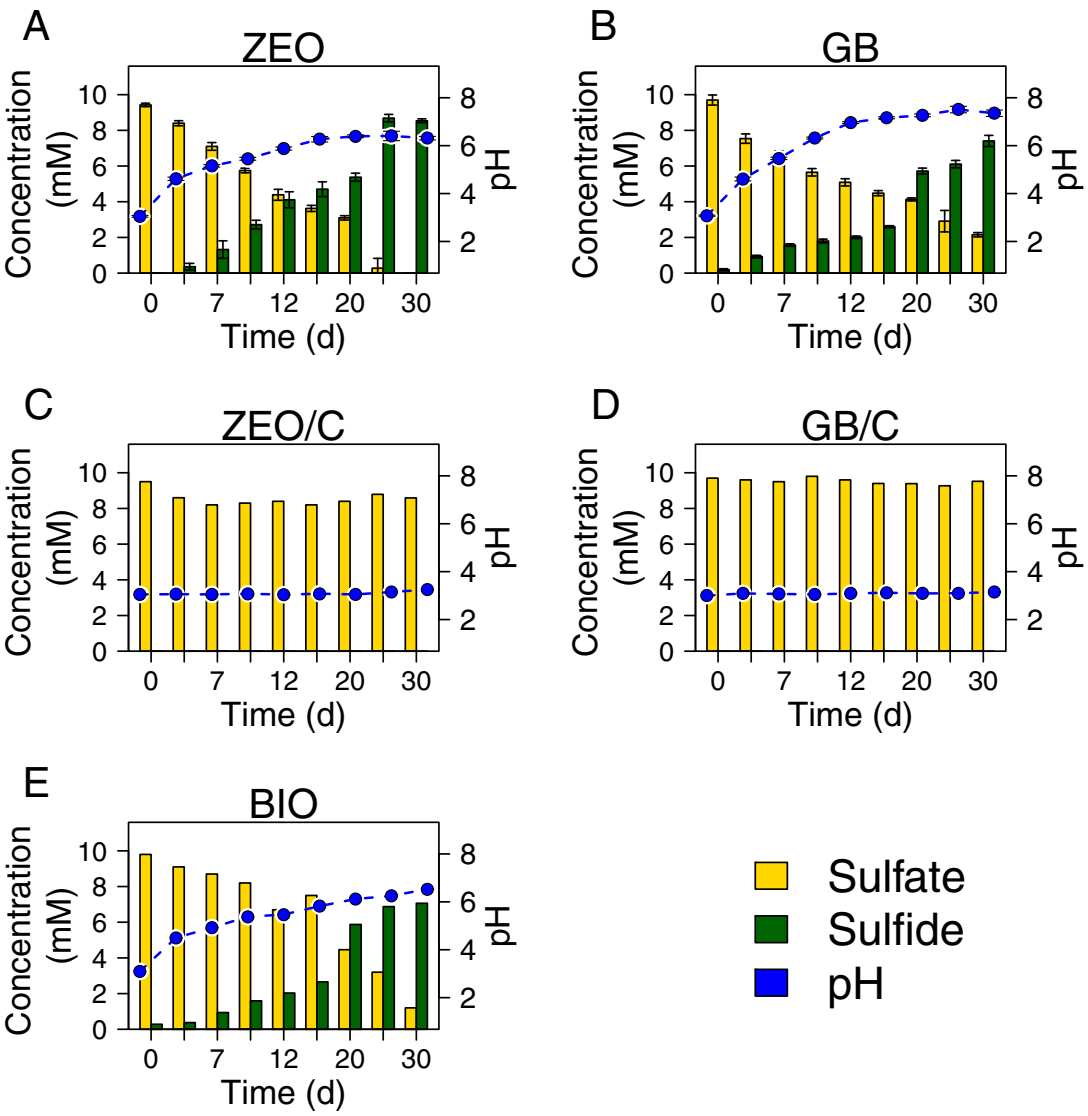

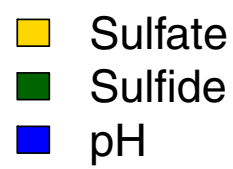

produced propionate was consumed by day 20 (Fig. 2B). In contrast, the acetate produced in the GAC assays was not completely consumed, and $1 \mathrm{mM}$ remained on day 30 (Fig. S2A). The analyses of the abiotic control experiments gave a better understanding of the possible effects of the carrier materials on the development of the sulfate-reducing process (Figs. 1, 2, and S2). The adsorption processes in glass beads are negligible because no substantial change occurred in sulfate $(\sim 9.3 \mathrm{mM}), \mathrm{pH}(\sim 3.08)$, and glycerol ( $\sim 5.5 \mathrm{mM})$ concentrations in the abiotic control (Figs. 1D and 2D). Conversely, when using zeolite or GAC, some adsorption and desorption effects were observed. With zeolite, there was a slight absorption of sulfate and glycerol, whereas the $\mathrm{pH}$ did not change ( 3.09) (Figs. 1C and 2C), but when comparing with the biotic experiments, the biological consumption of glycerol (Fig. 2A) predominated being faster than the absorption process (Fig. $2 \mathrm{C})$. The abiotic assays with GAC presented a more notorious effect of the adsorption/desorption of sulfate and glycerol showing maximum adsorption values, $\sim 5.68 \mathrm{mM}$ of sulfate and $4.6 \mathrm{mM} \mathrm{mM}$ of glycerol (Figs. S2D and C). The adsorption/desorption in the abiotic controls with zeolite and GAC was considered to calculate the sulfide concentration with these carrier materials.

Even though we did not determine the adsorption of acetate and propionate on zeolite or GAC in abiotic experiments, comparing with glass beads and with the biological control, we can infer that the absorption of acetate was not relevant.

\section{Rates of sulfate reduction in the batch assays}

The kinetic profiles obtained with zeolite, glass beads, and GAC and in the absence of carrier material (biological control) served to calculate the rates of acetate consumption and sulfide production, sulfide yield, and the percentage of substrate used for sulfate reduction (Table 1). The values obtained with zeolite were the highest, even higher than in the biological control; the electron donor was almost completely used for sulfate reduction $(\sim 90 \%)$, followed by the glass beads and the biological control ( $c a .70 \%)$. The assays with GAC used close to $60 \%$ of the substrate for sulfate reduction; acetate remained as by-product and was not further metabolized despite that glycerol was completely consumed (Fig. S2). Regarding the yield of sulfide, the assays with zeolite had the highest calculated yield of sulfide produced per glycerol consumed, followed by the glass beads, biological control, and GAC. Zeolite increased the yield of sulfide by $21 \%$ compared to the biological control with no carrier material. Accordingly, zeolite also showed the highest rates of sulfide production and acetate consumption, followed by the 
Fig. 2 Consumption of glycerol and formation of intermediaries with the different carrier materials and abiotic controls: A zeolite (ZEO), B glass beads (GB), C abiotic control of zeolite (ZEO/ C), $\mathbf{D}$ abiotic control of glass beads $(\mathrm{GB} / \mathrm{C})$, and $\mathbf{E}$ biological control (BIO) without carrier material
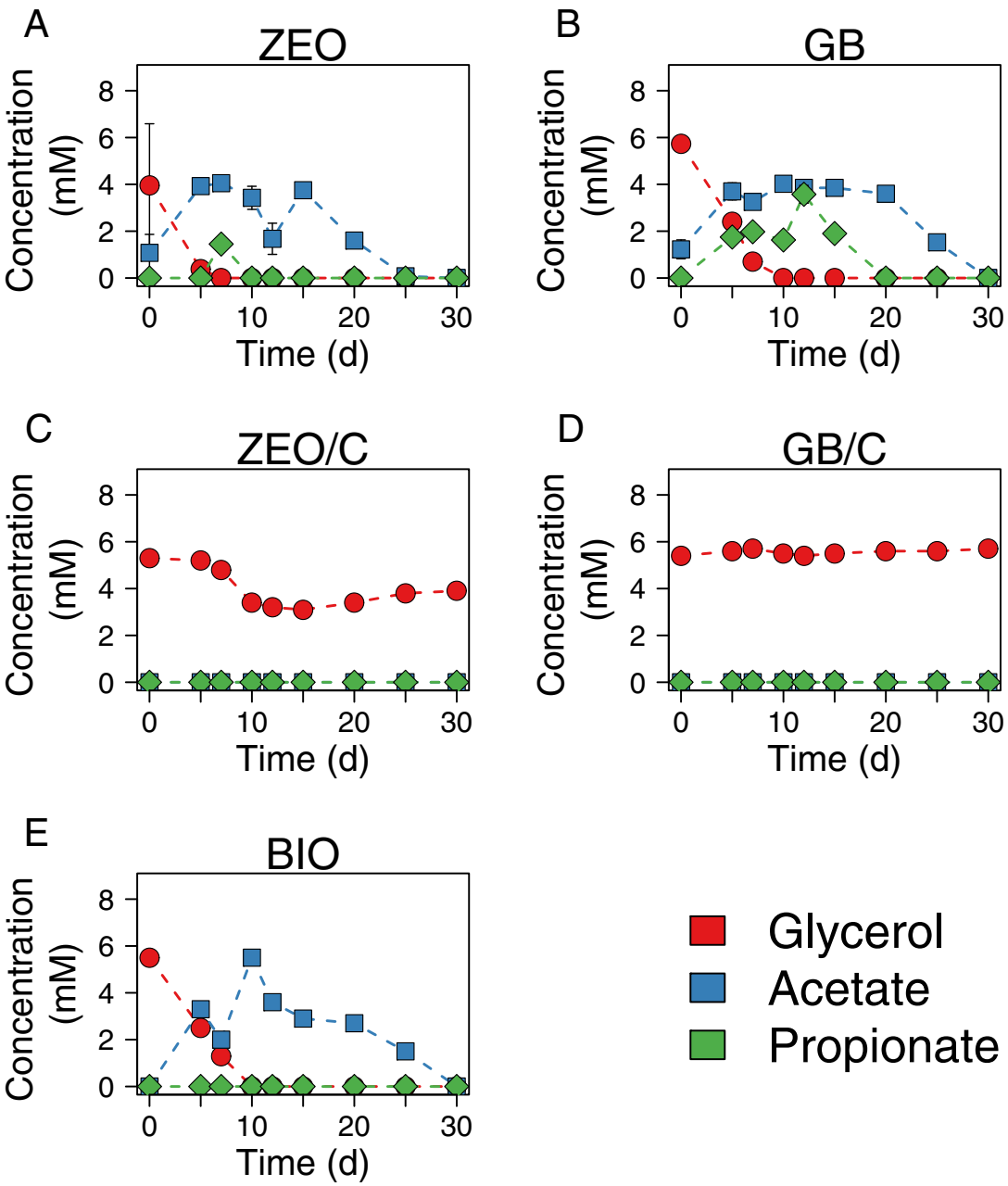

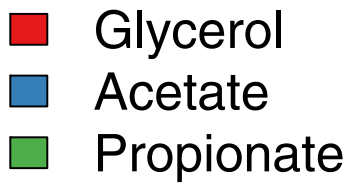

biological control, glass beads, and GAC. Considering these results, we discarded GAC as carrier material for further analysis.

SEM images helped to corroborate the attachment of microorganisms on zeolite and glass beads (Fig. S3). Initially, after inoculation (day 0), we observed the surface of both materials with practically no attached microorganisms. On days 7 and 10, when glycerol was depleted in the experiments with zeolite and glass beads, respectively, several microorganisms were attached to the surface of the materials indicating the initial formation of a biofilm. At the end of each experiment, on days 25 or 30, more microorganisms were attached to the surface of both materials (Fig. S3). The change in the aspect of the carrier materials (zeolite and glass beads) due to the formation of biofilms was also visible to the naked eye (Figs. S4 and S5).

\section{Microbial composition}

The community analysis of the DNA samples, withdrawn when glycerol and acetate were depleted, yielded information about the microorganisms attached to zeolite and glass beads

Table 1 Sulfide yield, percentage of substrate used for sulfate reduction, sulfide production rate, and acetate consumption rate with the different carrier materials and in the biological control without carrier material

\begin{tabular}{lllll}
\hline Experiment & $\begin{array}{l}\text { Yield }\left(\mathrm{mmol} \mathrm{H} \mathrm{H}_{2} \mathrm{~S} / \mathrm{mmol}\right. \\
\text { glycerol })\end{array}$ & $\begin{array}{l}\text { Substrate used for sulfate } \\
\text { reduction }(\%)\end{array}$ & $\begin{array}{l}\text { Sulfide production rate } \\
(\mathrm{mmol} / \mathrm{L} \mathrm{d})\end{array}$ & $\begin{array}{l}\text { Acetate consumption rate } \\
(\mathrm{mmol} / \mathrm{L} \mathrm{d})\end{array}$ \\
\hline Glass beads & $1.3 \pm 0.05$ & $72.7 \pm 0.43$ & $0.26 \pm 0.004$ & $0.20 \pm 0.012$ \\
Zeolite & $1.5 \pm 0.18$ & $92.6 \pm 1.2$ & $0.32 \pm 0.011$ & $0.40 \pm 0.032$ \\
Granular activated carbon & $0.98 \pm 0.13$ & $58.0 \pm 8.2$ & $0.14 \pm 0.024$ & $0.15 \pm 0.093$ \\
Biological control & 1.23 & 71.4 & 0.27 & 0.23 \\
\hline
\end{tabular}


and those that remained in the liquid (planktonic community). The OTUs richness ( $\mathrm{S}$ ) was different between the carrier materials, glass beads had the lowest richness, and the values were similar between the phases (planktonic and biofilm) (S $=30-38)($ Table S2). The samples from the zeolite experiments had the highest values of richness $(\mathrm{S}=48-61)$ in both phases. Accordingly, the Shannon-Wiener index $(\mathrm{H})$ indicated more diversity in the zeolite samples than in the glass beads samples (Table S2).

A total of 5,134,558 reads with an average of $\sim 190,168$ reads per sample were obtained. The taxonomic affiliation at the family level revealed that a total of 46 OTUs composed the communities (Figs. 3 and 4). All the samples, including the inoculum, shared a basic core of four families (relative abundance $>1 \%$ ) Clostridiaceae, Desulfovibrionaceae, Porphyromonadaceae, and Ruminococcaceae. The inoculum was dominated by Ruminococcaceae $(55 \pm 4.5 \%)$, followed by Desulfobacteraceae $(11.2 \pm 2.0 \%)$, Lentimicrobiaceae $(9.0$ $\pm 0.8 \%)$, and Clostridiaceae $(5.5 \pm 0.8 \%)$. The relative abundances of Desulfovibrionaceae, Porphyromonadaceae, Family XI, Caldisericaceae, Mesoaciditogaceae, Pseudomonadaceae, Spirochaetaceae, and Thermodesulfobiaceae were between 4 and $1.1 \%$; the rest of the families were represented in less than
$1 \%$, including families related to the sulfur cycle (Desulfurellaceae and Peptococcaceae, Figs. 3 and 4).

The structure of the community was different depending on the carrier material, the type of sample (planktonic/biofilm), and the incubation stage (early/late). For instance, in the incubations with zeolite (Fig. 4), Clostridiaceae (37-51\%) was consistently the most abundant family in all the samples (planktonic/biofilm). Members of the other families were mainly present in the carrier material in the early (7 days) and late stages (25 days), such as Ruminococcaceae (15.6 and $12.8 \%$, respectively). Conversely, Peptococcaceae, initially abundant in the planktonic community $(32.3 \%)$, was found mostly attached to the carrier material $(22.7 \%)$ than in the liquid (4.5\%) after 25 days. It is worth to note that the relative abundance of Peptococcaceae in the inoculum was low $(0.07 \%)$. Overall, in the late stage ( 25 days) of the assays with zeolite, the biofilm held seven dominating families with relative abundances higher than $1 \%$ : Clostridiaceae (40.2\%), Peptococcaceae $(22.7 \%)$, Ruminococcaceae (12.8\%), Desulfurellaceae (6.8\%), Porphyromonadaceae (4.3\%), Desulfobacteraceae (2.2\%), and Desulfovibrionaceae (1.9\%).

With glass beads (Fig. 3), the structure of the communities of the liquid phase changed with time; the most abundant
Fig. 3 Heatmap of the microbial community at the family level in the experiment with glass beads. SOL denotes the biofilm community developed over the carrier material and LIQ the planktonic community, in the early (day 10) and late (day 30) stages. The community of the inoculum is also shown. The number after the period indicates the number of the replica

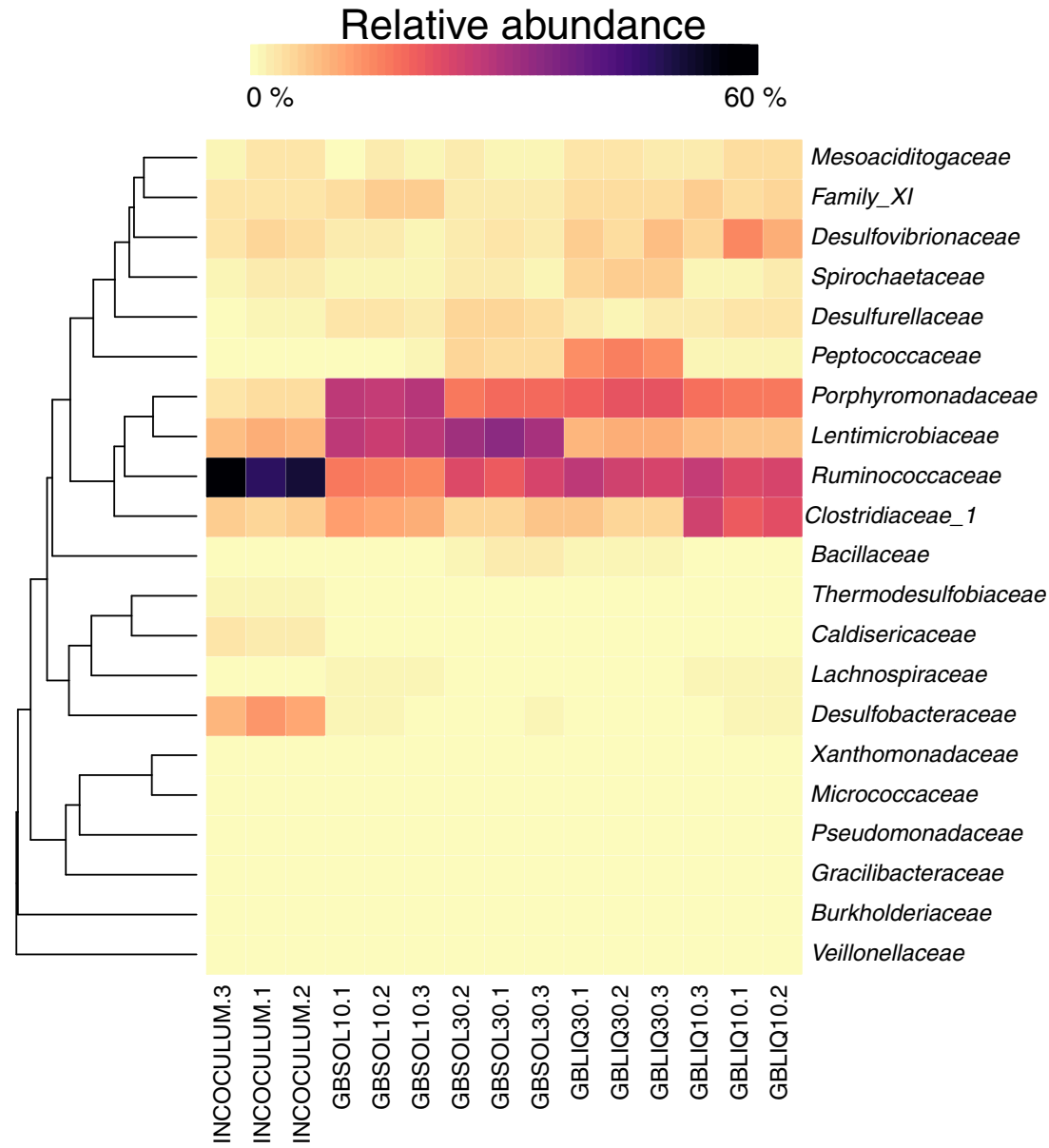


Fig. 4 Heatmap of the microbial community at the family level in the zeolite experiments. Samples from the biofilm are identified as SOL and those from the liquid phase as LIQ, at the early (day 7) and late (day 25) stages of the experiments, in comparison with the inoculum. The number after the period indicates the number of the replica

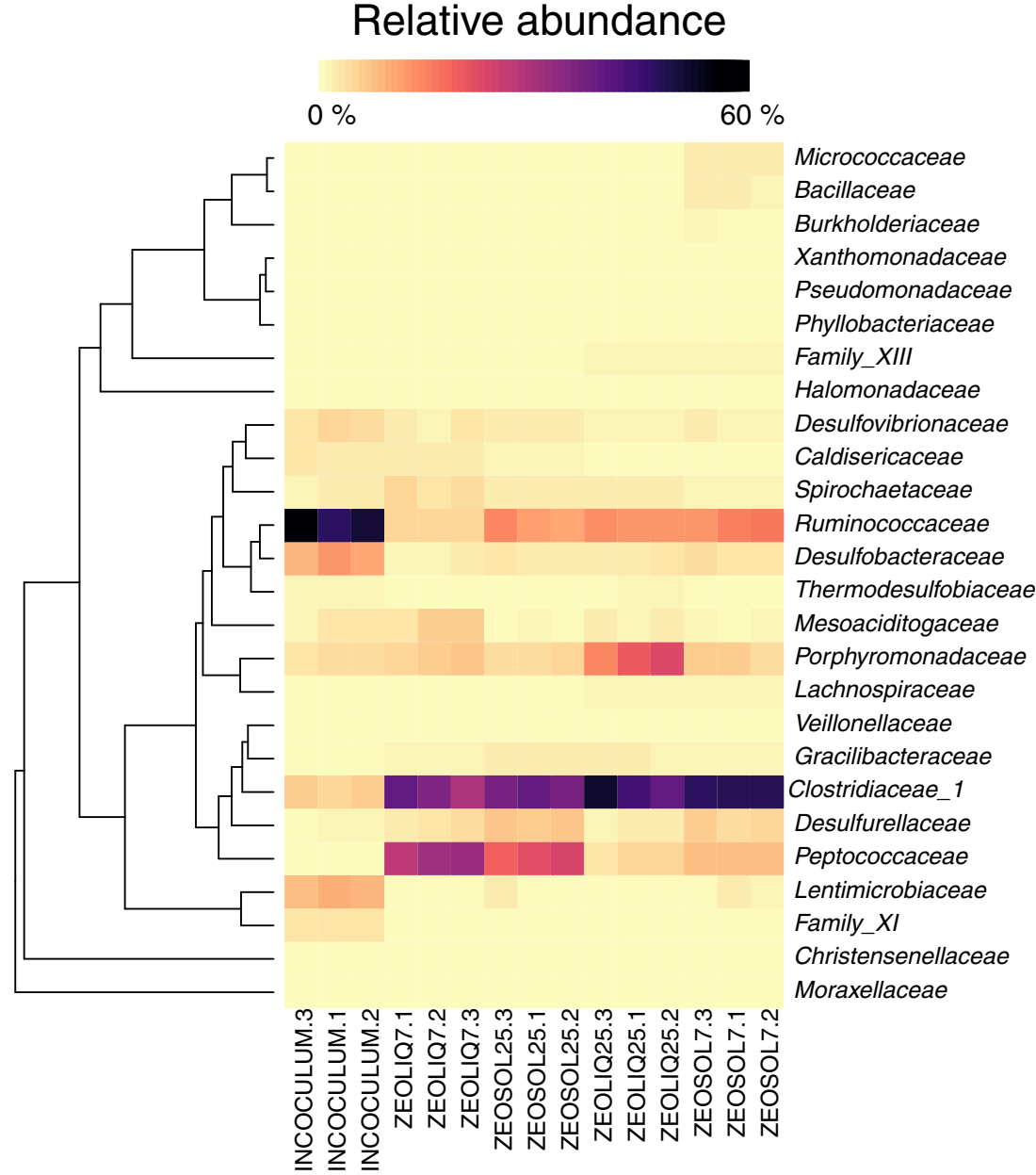

families (relative abundance $>5 \%$ ) in the early stage (10 days) were Ruminococcaceae (24.6\%), Clostridiaceae $(23.3 \%)$, Desulfovibrionaceae (10\%), Lentimicrobiaceae (7.30\%), and Family XI ( $5.2 \%)$. The relative abundances of Porphyromonadaceae, Desulfurellaceae, and Peptococcaceae were between 4.3 and $1 \%$. Glass beads did not favor the attachment of Clostridiaceae because the relative abundance of this family in the biofilm at day 30 was only $5.7 \%$. Also, the relative abundance of Desulfovibrionaceae decreased to $2.3 \%$, whereas in the biofilm community (30 days), the relative abundance of Lentimicrobiaceae and Porphyromonadaceae sequences increased to 33.4 and $18.5 \%$, respectively.

The diversity of the sulfur cycle microorganisms (Fig. 5) revealed the affiliation to two classes (Deltaproteobacteria and Clostridia), five families (Desulfovibrionaceae, Desulfobacteraceae, Desulfurellaceae, Peptococcaceae, and Thermodesulfobiaceae), and six genera (Desulfovibrio, Desulfatirhabdium, Desulfurella, Desulfotomaculum, Desulfosporosinus, and Thermodesulfobium). Except for Desulfurella, which has only a sulfur-reducing metabolism, the other genera are sulfate reducers. In the zeolite assays, depending on the stage and the type of sample (planktonic or biofilm), the microorganisms of the sulfur cycle represented between 7.3 and $35.7 \%$ of the community of all the samples; with glass beads, the percentages were lower between 5.5 and 14.1\% (Fig. 5).

Some of the identified SRM preferred to be attached to the carrier material. For example, in the experiments with zeolite after 25 days, the relative abundance of Desulfotomaculum reached $18.9 \%$ compared to the abundance found in the liquid (1.2\%). Desulfurella was also detected in the biofilm in higher abundances (5.0 and 6.8\%) than in the liquid (2.9 and 1.6\%), irrespectively of the stage. In contrast, the relative abundances of Desulfovibrio (1.2-1.9\%), Desulfosporosinus (0.5-1.0\%), and Thermodesulfobium $(0.3-0.5 \%)$ were approximately the same in the liquid and the biofilm. Interestingly, after 25 days, the relative abundance of the sulfur cycle microorganisms decreased in the planktonic community of zeolite from 36 to $7.3 \%$; with the consequent increase in the biofilm to $31 \%$ (Fig. 5).

In the experiments with glass beads, the relative abundances of Desulfurella were higher in the biofilm (4.6\%) than in the liquid (1.4\%) at the end of the experiment (30 days, Fig. 5). Desulfovibrio showed the highest relative abundances $(10 \%)$ in the liquid phase and in the early stage. It appeared that Desulfovibrio could not attach to the glass beads. The 
Fig. 5 Heatmap of the sulfur cycle microbial community at genus level with zeolite (ZEO, top panel) and glass beads (GB, bottom panel) in the different matrices liquid (LIQ) or solid (SOL) in the early stage, day 7 or 10 , and in the late stage, day 25 or 30 . The community of the inoculum is also shown. The number after the period indicates the number of the replica
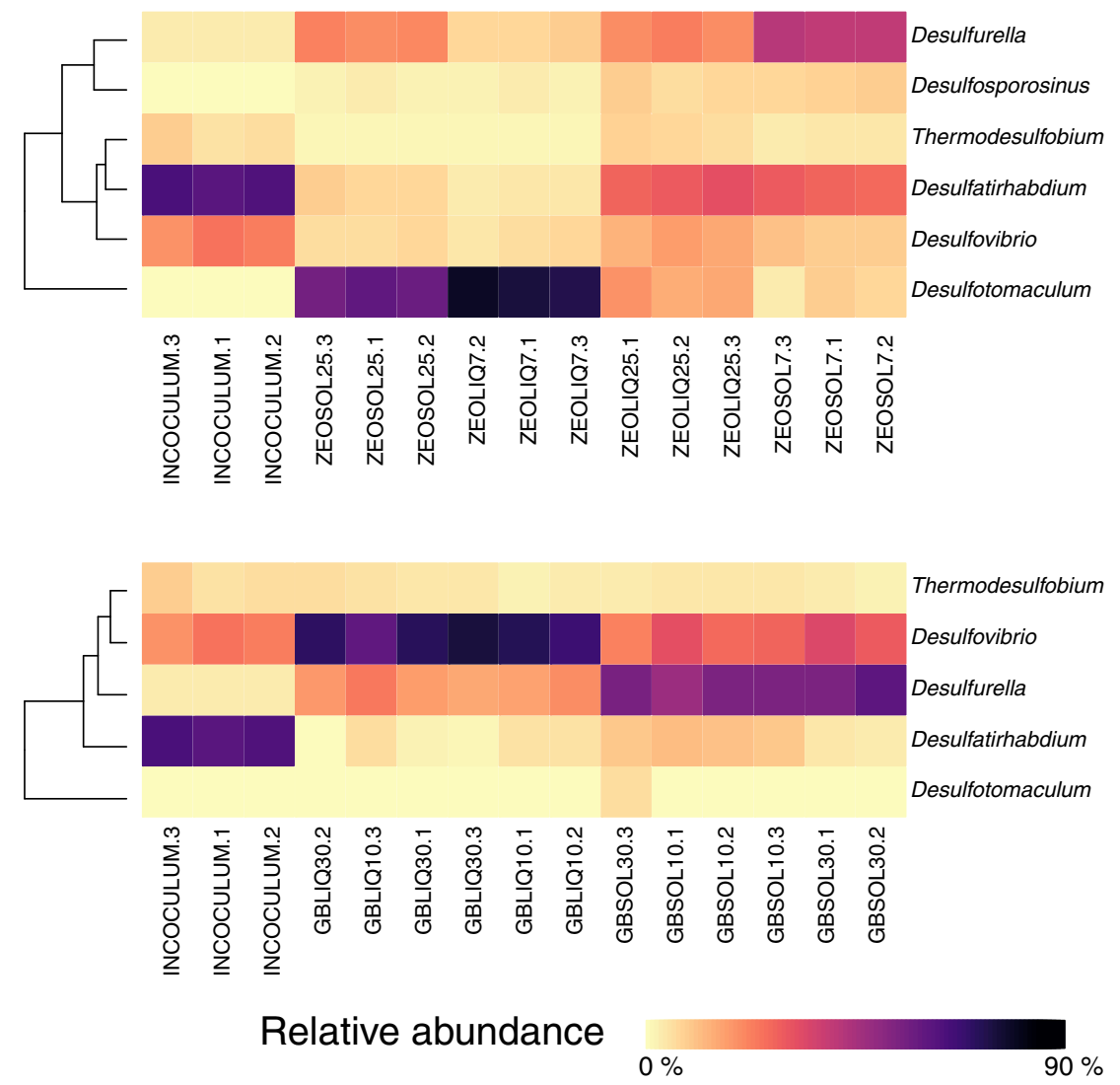

other genera (Desulfatirhabdium, Thermodesulfobium, Desulfosporosinus, and Desulfotomaculum) had relative abundances lower than $1 \%$, and it was difficult to identify a preference for the carrier material (Fig. 5).

The non-metric multidimensional scaling (NMDS) analysis showed that the communities developed with the carrier materials are different from each other and the inoculum (Fig. 6). The redundancy analysis (RDA) indicated that the constrained variance represented $73 \%$ of the total variance, suggesting that most of the variation in the composition of the communities may be accounted for the combination of time, phase (planktonic/biofilm), and the type of carrier (Fig. 6). Zeolite and glass beads grouped in different quadrants, indicating that the communities of the two carrier materials were different. Further, the communities from the liquid and biofilm of both materials were also different. In the case of glass beads, the planktonic communities grouped depending on the sampling time (10 or 30 days), unlike the biofilm communities. In the case of zeolite, the communities from the liquid were different from those of the biofilm, regardless of the sampling time (Fig. 6).

\section{Discussion}

At acidic conditions, sulfate-reducing biofilms formed with zeolite and glass beads, but the extent of the sulfate-reducing process and the community structure depended on the carrier material. Some SRM were more present in the biofilm, and others in the planktonic phase; even though SRM did not dominate the microbial communities, the sulfide production yield and percentage of the substrate used to perform sulfate reduction improved.

The complex communities developed on zeolite and glass beads in the biofilm and planktonic phase differed from the original planktonic culture (inoculum); nevertheless, the most important feature that interested us, which was the complete oxidation of acetate, was achieved at acidic pH. Here, we show that the communities developed with zeolite and glass beads degraded acetate at acidic $\mathrm{pH}$ while preserving the sulfate-reducing activity of the inoculum. In contrast, the community formed with GAC did not degrade acetate at the same rate (Table 1), despite the concentration of acetate was lower than that observed with glass beads or zeolite (Figs. 2 and S2). Acetate degradation in sulfate-reducing systems at acidic $\mathrm{pH}$ is relevant because acetate may be toxic for microorganisms (Sánchez-Andrea et al. 2014); the protonated volatile fatty acids diffuse through the cellular membrane and decouple the electron transport chain. Concentrations as low as $1 \mathrm{mM}$ may be toxic for acidophilic microorganisms (Kaksonen and Puhakka 2007). Although in experiments with zeolite and glass beads the maximum concentration of protonated acids was $2.1 \mathrm{mM}$ (pH 5.15) and $3.9 \mathrm{mM}(\mathrm{pH} 4.6)$, respectively, the 
Fig. 6 Non-metric multidimensional scaling (NMDS) plot and redundancy analysis (RDA) of the microbial communities obtained with zeolite (ZEO) or glass beads (GB) in the different matrices liquid (LIQ) or biofilm (SOL), sampled at 7 , 10,25 , or 30 days
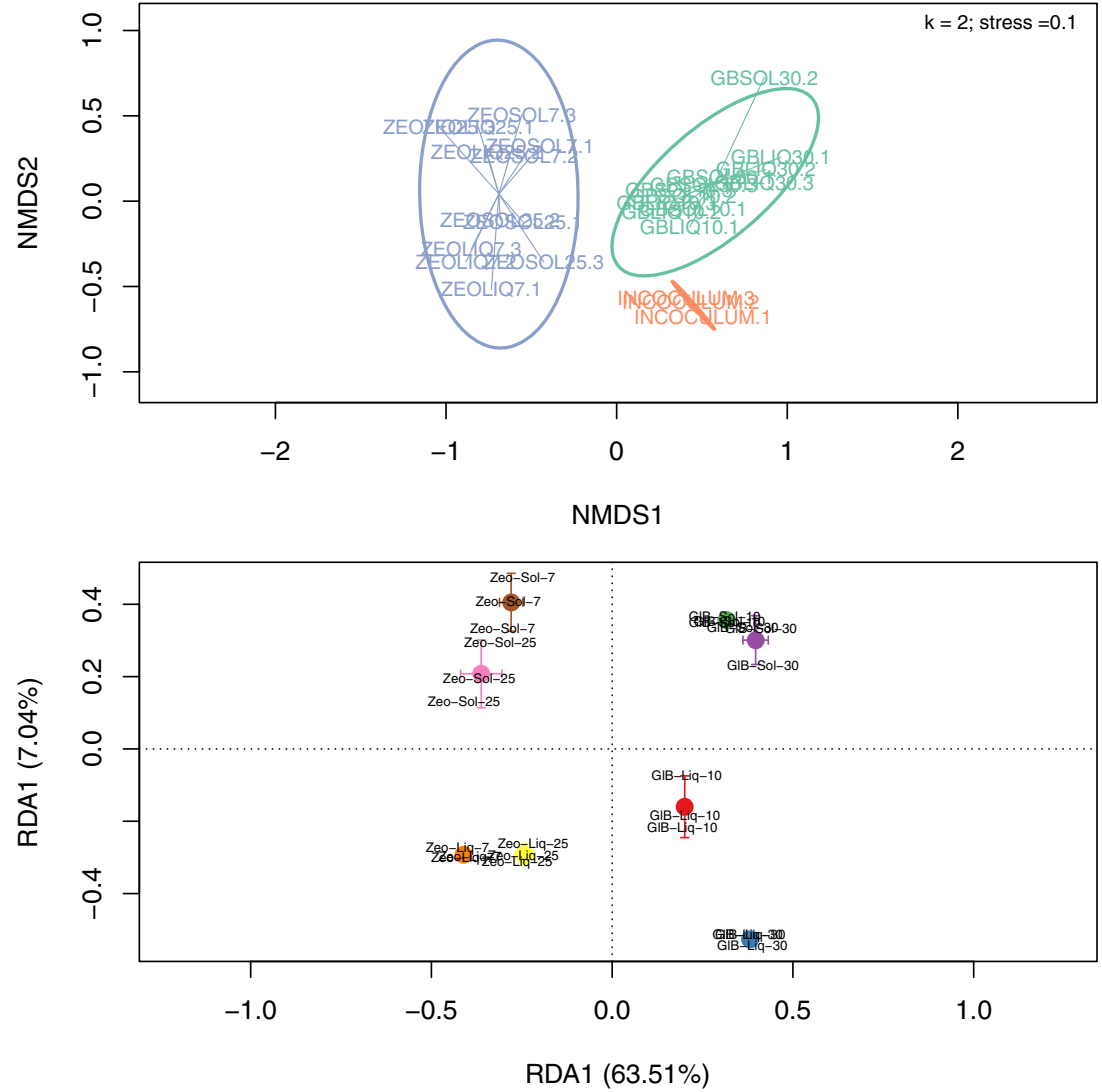

communities were able to degrade acetate once the $\mathrm{pH}$ surpassed the pKa of acetic acid (4.76). This result confirmed the importance of acetate oxidation to increase the $\mathrm{pH}$ when remediating acidic currents (Kaksonen et al. 2003). Overall, acetate degradation in sulfate-reducing systems increases the efficiency of the process. The degradation of acetate in our experiments allowed reaching substrate consumption efficiencies via sulfate reduction as high as 58-92.6\%, which is in contrast with other works reporting close to $50 \%$ of substrate consumption via sulfate reduction (Nancucheo et al 2012). A relevant aspect of our study is that we screened for SRM in the biofilms and in the liquid phase of the experiments. Two acetate degraders were present in the communities of the assays with zeolite: Desulfotomaculum in the biofilm and Desulfatirhabdium in the planktonic phase (Kleikemper et al. 2002; Balk et al. 2008). Desulfotomaculum, member of the Peptococcaceae family, is a spore-forming sulfate-reducing bacteria (Castro et al. 2002). This genus is very heterogeneous and has recently been reclassified including some complete oxidizing species; members of this genus have been found in sediments, deep surface samples, lakes, and pits, and have also been used to remediate AMD (Aüllo et al. 2013; Watanabe et al. 2018). In the inoculum, Peptococcaceae family was underrepresented $(<1 \%)$; some members of this family (e.g., Desulfotomaculum and Desulfosporosinus) are important sulfate reducers in acidic environments (Sánchez-Andrea et al. 2013; Nancucheo and Johnson 2014; Sánchez-Andrea et al. 2014). Desulfatirhabdium is a genus classified as a complete oxidizer that can use a wide variety of substrates and has genes that confer resistance to acid and metals (Kuever 2014; Almstrand et al. 2016) that might explain its presence in our systems. Members of these two genera may be responsible for the $\sim 21 \%$ improvement of the sulfate-reducing performance using zeolite. In contrast, the overall performance with glass beads was very similar to the performance in the absence of carrier material. Previously, glass beads were used as an ideal support material for the adhesion of sulfate-reducing communities at acid $\mathrm{pH}$ in continuous reactors (Nancucheo and Johnson 2012; Santos and Johnson 2018). In this work, glass beads did not promote the attachment of members of the Peptococcaceae family (such as Desulfotomaculum or Desulfosporosinus) as compared with zeolite. Glass beads were not an appropriate carrier material for the acetatedegrading SRM that were present in the inoculum (i.e., Desulfotomaculum and Desulfatirhabdium).

The well-known sulfate-reducing genus Desulfovibrio grew mostly in the liquid phase, which was more evident in the experiment with glass beads. This genus belongs to the family Desulfovibrionaceae that comprises incomplete oxidizers. Some members of Desulfovibrio can oxidize glycerol (Kremer and Hansen 1987; Qatibi et al. 1998) and have been 
found in acidic streams such as acidic lakes, wetlands, acidic sulfate soils, and bioreactors (Sánchez-Andrea et al. 2014).

Using glycerol as substrate, the communities with zeolite and glass beads achieved complete oxidation of the substrate, including acetate, reaching 58-92\% of sulfate-reducing activity (Table 1). Typically, glycerol has been used to develop acidic sulfate reduction at low $\mathrm{pH}(<5)$, both in batch cultures $(\sim 30-85 \%$ sulfate reduction activity) (Dinkel et al. 2010; Moreno-Perlin et al. 2019) and in continuous reactors $(\sim 15-$ 75\%) (Nancucheo and Johnson 2012; Santos and Johnson 2017). However, the complete oxidation of acetate is not always achieved, which is the main drawback of sulfate reduction at acidic $\mathrm{pH}$ specially in continuous systems, most probably due to the lack of complete oxidizers and acetate cannot be degraded (Santos and Johnson 2018). In the present work, the success of the starting community in degrading acetate may be related to the fact that it has been cultured at acidic $\mathrm{pH}$ for more than 3 years and its performance is very reproducible (Campos-Quevedo et al. 2020). Therefore, there was no need to do any bioaugmentation of the microbial community with an acetoclastic acidophile (e.g., Acidocella aromatica) to improve the degradation of acetate, as previously reported (Nancucheo et al. 2017).

Despite performing sulfate reduction with high efficiencies, the communities developed over zeolite and glass beads were not dominated exclusively by SRM (Figs. 3 and 4) and were statistically different from the inoculum (Fig. 6). Instead, complex communities developed on the biofilm and planktonic phase of both carrier materials, which allowed SRM to resist stress conditions such as the presence of acetate at acid $\mathrm{pH}$.

Low-abundance microorganisms still may play a crucial role in the global process by developing different mechanisms to thrive over adverse conditions and proliferate when favorable conditions prevail, as pointed out before (Hausmann et al. 2016); this could be the case of Desulfosporosinus and Thermodesulfobium (Fig. 5). Some species of Desulfosporosinus genus have been found in acid mine drainage, and some of them can resist moderate acidic conditions (Alazard et al. 2010). Thermodesulfobium genus has been described in enrichments of an acidic pit lake (pH 3 and 4) suggesting that sulfate-reducing communities were better adapted to extreme conditions (Meier et al. 2012). On the other hand, the fermentative microorganisms (i.e., Ruminococcaceae and Clostridiaceae) present in the biofilm and in the liquid phase could be responsible for the formation of exopolymeric substances and may helped SRM to survive and handle stressful conditions through synergetic associations (Sánchez-Andrea et al. 2012).

From the four families that dominated all the analyzed communities, members of Clostridiaceae could be responsible for glycerol fermentation and the production of propionic acid in zeolite and glass beads, GAC being the exception in which propionic was not observed as in the biological control (Figs.
2 and S2). Representatives of this family are very conspicuous in anaerobic communities and have been found in samples of acid mine drainage, sulfate-reducing consortia, and sediments ( $\mathrm{Lu}$ et al. 2011; Reyes et al. 2017). Members of the family Ruminococcaceae have been previously described in microbial communities of a sulfate-reducing bioreactor operated at pH 5 to 6.5 (Shan et al. 2017) and along with sulfate-reducing bacteria in ferruginous sediments (Vuillemin et al. 2018). On glass beads (Fig. 4), the majority of the sequences resembling Peptococcaceae family were similar to Sporotomaculum genus, mostly found in the liquid phase at day 30 . It is plausible that their role in the consortium was as fermenters because the cultured representatives cannot use sulfate as an electron acceptor (Brauman et al. 1998).

The results also show important differences between the communities in the early/late stages of the biofilm or liquid phase. In other studies, this issue has remained unexplored highlighting that there is a lack of information about the communities developed in the early stages of sulfate-reducing biofilms at acidic $\mathrm{pH}$, specially of those that degrade acetate. Therefore, the information presented here becomes useful when implementing sulfidogenic cultures in continuous biofilm reactors under acidic conditions. The study of the biofilm communities in the early and late stages also allowed knowing the time needed for the SRM to adhere to the support material (biofilm formation).

Overall, starting with the same inoculum, the carrier materials (glass beads or zeolite) shaped the attachment and development of different microbial communities. Our results confirmed previous observations with sulfate-reducing bacteria (Basu and Baldwin 2000) or soil communities (Aminiyan et al. 2018). The effect of the carrier material was also confirmed by diversity indexes and statistical analysis, showing that such difference was significant (Fig. 6 and Table S2). These observations underline that the carrier material is a decisive factor in the formation of biofilms and, consequently, in the performance of biofilm reactors as noted before (Basu and Baldwin 2000; Silva et al. 2006). The development of biofilms over carrier materials is multifactorial and depends on the surface properties of both the carrier material and bacteria. Surface roughness, hydrophobicity, the composition of the carrier material, and species of bacteria are among the most relevant characteristics that determine bacterial attachment (Pereira et al. 2000; Hadjiev et al. 2007). Roughness has been highlighted as more important than internal surface area for bacterial colonization because the surface irregularities (crevices, cracks, grooves, etc.) promote initial colonization (Pereira et al. 2000) and protect microorganisms from abrasion/detachment. Internal pore size, which relates to the specific surface area, can be an important characteristic as long as $70 \%$ of the pores have diameters in the micrometric scale. For bacterial colonization, the pores should be between one time the smallest dimension of the bacteria and five times the 
largest one (Oliveira et al. 2003). In our study, none of the three carrier materials meet this condition, because the internal pore size of zeolite, glass beads, and activated carbon is in the nanometric scale (Huysman et al. 1983). Regarding hydrophobicity, this feature has an impact on the interaction forces between bacteria and the carrier material; these forces become stronger when water is "squeezed out" allowing the contact between bacteria and the carrier material (Pereira et al. 2000; Habouzit et al. 2011). Given this complexity, the selection of the carrier material based on kinetic assays may represent an advantage versus using a carrier material based only on its physicochemical characteristics (i.e., superficial area, hydrophobicity, and charge, among others).

The use of carrier materials under acidic conditions has been widely studied due to the advantages that the carrier provides to the community, such as preventing washout by biofilm formation, allowing high flows, and increasing the cellular retention time (Basu and Baldwin 2000; Silva et al. 2006); these advantages allow to operate high-rate continuous reactors. With zeolite, the change of the community composition had a positive effect on the sulfate-reducing process; this material promoted faster kinetics and improved the efficiencies and yield compared with the original acid-tolerant consortium used as the inoculum. In contrast, the change of the community with glass beads was not reflected in the global performance of the assays, which performed similar to the assay without carrier. Most probably, the differences between zeolite and glass beads communities are due to the surface roughness of the carriers; being zeolite of irregular shape with a rough surface, it presented more crevices for initial colonization than the regular shape and smooth surface provided by glass beads. The cation exchange feature of zeolites could also contribute to this difference as previously reported (Kubota et al. 2008; Wang and Peng 2010). Exploring different carrier materials in kinetic experiments to reproduce the activity observed in liquid culture is worth to reveal the performance beforehand running a reactor.

Previously, biofilms of acidophilic sulfate reducers formed on GAC were reported to achieve high removal efficiencies of sulfate (75-90\%) (Sánchez-Andrea et al. 2012). Despite the suitability of GAC to sustain the growth of SRM, in the present study, GAC showed the lowest sulfate reduction rate of all the evaluated carrier materials, and acetate remained as byproduct. One drawback of using GAC or zeolite as carrier materials is that it was not possible to quantify the concentration of sulfide in the liquid phase, due to the nature of the materials with high porosity and surface area and with a suite of functional groups that can adsorb sulfide (Liu and Adanur 2014; Tran et al. 2016).

The main functional groups that compose GAC of basic character, as Norit $830 \mathrm{~W}$, include chromene structures, diketone or quinone groups, and pyrone-like groups (Montes-Morán et al. 2004). Due to its adsorption capacity and high surface area, GAC has been used as carrier material to form biofilms in several biotechnological applications and also for the adsorption of sulfide (Coppola and Papurello 2018). The results of the abiotic controls highlight the importance of accounting for the adsorption contribution of each material.

Although adsorption and desorption of glycerol, sulfate, and acetate occurred with zeolite and GAC, in the case of zeolite, these substrates remained bioavailable despite their absorption, as confirmed by the sulfate-reducing activity. Conversely, the bioavailability of glycerol, acetate, and sulfate was compromised when GAC was used as the carrier material. Both materials contain functional groups that promote adsorption of different compounds that have no adverse effect on the microorganisms and can be considered as "inert" carrier materials. Nonetheless, their use in sulfate-reducing batch assays should be analyzed carefully, moreover if metals are involved. Eventually, the absorption of sulfide will reach a saturation point, explaining the successful application of these materials for metal precipitation in continuous reactors (Bertin et al. 2004; Sánchez-Andrea et al. 2012). From this perspective, glass beads could be an ideal inert carrier material as they did not interfere with the concentrations of sulfate and glycerol in the abiotic controls. Earlier, glass beads were used for the attachment of sulfate-reducing communities at acidic $\mathrm{pH}$ in continuous reactors (Santos and Johnson 2018; Santos and Johnson 2017; Nancucheo and Johnson 2014; Sahinkaya et al. 2011). Overall, the results allowed us to select glass beads and zeolite as appropriate carrier materials for the acidophilic sulfate-reducing consortium because both carrier materials preserved the main characteristic of interest: acetate consumption at acidic $\mathrm{pH}$. Any of these carrier materials could be used in future applications of the consortium to maintain the community within a continuous reactor.

Despite the noticeable change of the microbial community with zeolite and glass beads, compared with the initial sulfatereducing community, the complete consumption of acetate at low $\mathrm{pH}$ prevailed. With glass beads, the performance was almost the same as the inoculum; however with zeolite, the change of the community enhanced the yield and the sulfatereducing activity. These sulfate-reducing communities on zeolite and glass beads could be applied to remediate metalcontaining effluents, which are typically acidic.

The present study contributes to understand that sulfatereducing communities thriving at acidic conditions are complex and do not need to be dominated by SRM and that the communities initially attached to the biofilm may change as the biofilm matures. The carrier material determined the community development of the biofilm, and a proper choice is crucial for the whole sulfate-reducing process.

This study also demonstrated that the preference of the SRM to attach or remain planktonic depends on the carrier material; Desulfotomaculum preferably attached to zeolite, 
and Desulfovibrio to glass beads in the late stage of the batch incubations (25-30 days). In the planktonic phase, Desulfatirhabdium remained present in the zeolite experiments, and Desulfovibrio in glass beads. This work underlines the critical role of abiotic controls and having an inoculum already acclimated to specific conditions, in this case, sulfate reduction at acid $\mathrm{pH}$ and complete consumption of acetate. Overall, here we highlight the importance of a proper startup strategy when developing acidophilic sulfate-reducing biofilms in a possible application such as continuous highrate reactors to treat acidic metal-containing effluents. Glass beads preserved the sulfate-reducing activity of the inoculum, whereas zeolite enhanced the activity; these two materials could be applied successfully to treat acidic streams with metals in high-rate continuous reactors.

Supplementary Information The online version contains supplementary material available at https://doi.org/10.1007/s00253-021-11365-0.

Acknowledgements The authors acknowledge the technical support of Ton van Gelder and Steven Aalvink. The use of the infrastructure of the Laboratory of Microbiology at Wageningen University is gratefully acknowledged. We also thank Dr. Aura Ontiveros, Dr. César Nieto, and the anonymous reviewers for their helpful comments and suggestions that improved the manuscript.

Author Contribution All authors contributed significantly to this work. NCQ, LBC, and ISA conceived and designed the experiments. NCQ conducted experiments, analyzed data, and drafted the manuscript. ISA, AJMS, and ERF contributed analytical tools and data analysis. TMP contributed to data inventory and R statistical analysis. All authors analyzed and interpreted data. All authors critically revised the manuscript and approved the final version.

Funding This research was financially supported by Netherlands Ministry of Education, Culture, and Science and the Netherlands Science Foundation through SIAM Gravitation grant 024.002.002.

Data availability The datasets of the next-generation sequencing are deposited in the NCBI BioProject database with accession number PRJNA646005 (https://www.ncbi.nlm.nih.gov/bioproject/?term= PRJNA646005). All other data generated or analyzed during this study are included in this manuscript (and its supplementary information file).

\section{Declarations}

Ethics approval This article does not contain any studies with human participants or animals performed by any of the authors.

Supplementary Information The online version contains supplementary

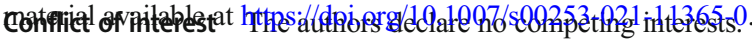

\section{References}

Alazard D, Joseph M, Battaglia-Brunet F, Cayol J-L, Ollivier B (2010) Desulfosporosinus acidiphilus sp. nov.: a moderately acidophilic sulfate-reducing bacterium isolated from acid mining drainage sediments. Extremophiles 14:305-312. https://doi.org/10.1007/ s00792-010-0309-4

Almstrand R, Pinto AJ, Figueroa LA, Sharp JO (2016) Draft genome sequence of a novel Desulfobacteraceae member from a sulfatereducing bioreactor metagenome. Genome Announc 4:e1540-15. https://doi.org/10.1128/genomeA.01540-15

Aminiyan MM, Hosseini H, Heydariyan A (2018) Microbial communities and their characteristics in a soil amended by nanozeolite and some plant residues: short time in-situ incubation. Eur J Soil Sci 7:9 19. https://doi.org/10.18393/ejss.327900

Aüllo T, Ranchou-Peyruse A, Ollivier B, Magot M (2013) Desulfotomaculum spp. and related gram-positive sulfate-reducing bacteria in deep subsurface environments. Front Microbiol 4:362. https://doi.org/10.3389/fmicb.2013.00362

Ayangbenro AS, Olanrewaju OS, Babalola OO (2018) Sulfate-reducing bacteria as an effective tool for sustainable acid mine bioremediation. Front Microbiol 9:1986. https://doi.org/10.3389/fmicb.2018. 01986

Balk M, Altinbaș M, Rijpstra WI, Sinninghe Damsté JS, Stams AJ (2008) Desulfatirhabdium butyrativorans gen. nov., sp. nov., a butyrateoxidizing, sulfate-reducing bacterium isolated from an anaerobic bioreactor. Int J Syst Evol Microbiol 58:110-115. https://doi.org/ 10.1099/ijs.0.65396-0

Baskaran V, Nemati M (2006) Anaerobic reduction of sulfate in immobilized cell bioreactors, using a microbial culture originated from an oil reservoir. Biochem Eng J 31:148-159. https://doi.org/ 10.1016/J.BEJ.2006.07.007

Basu O, Baldwin SA (2000) Attachment and growth of sulphate-reducing bacteria on different support materials. Environ Technol 21:12931300. https://doi.org/10.1080/09593332108618160

Battaglia-Brunet F, Crouzet C, Burnol A, Coulon S, Morin D, Joulian C (2012) Precipitation of arsenic sulphide from acidic water in a fixedfilm bioreactor. Water Res 46:3923-3933. https://doi.org/10.1016/j. watres.2012.04.035

Bertin L, Chiara Colao M, Ruzzi M, Fava F (2004) Performances and microbial features of a granular activated carbon packed-bed biofilm reactor capable of an efficient anaerobic digestion of olive mill wastewaters. FEMS Microbiol Ecol 48:413-423. https://doi.org/ 10.1016/j.femsec.2004.03.009

Brauman A, Müller JA, Garcia JL, Brune A, Schink B (1998) Fermentative degradation of 3-hydroxybenzoate in pure culture by a novel strictly anaerobic bacterium, Sporotomaculum hydroxybenzoicum gen. nov., sp. nov. Int J Syst Bacteriol 48:215221. https://doi.org/10.1099/00207713-48-1-215

Broenkow WW, Cline JD (1969) Spectrophotometric determination of hydrogen sulfide in natural waters. Limnol Oceanogr 14:454458. https://doi.org/10.4319/1o.1969.14.3.0454

Campos-Quevedo NG, Sánchez-Andrea I, López-Lozano NE, Stams AJM, Celis LB (2020) In search of sulfate-reducing consortia able to degrade acetate under acidic conditions. J Chem Technol Biotechnol 96:1228-1236. https://doi.org/10.1002/jctb.6635

Castro H, Reddy KR, Ogram A (2002) Composition and function of sulfate-reducing prokaryotes in eutrophic and pristine areas of the Florida everglades. Appl Environ Microbiol 68:6129-6137. https:// doi.org/10.1128/AEM.68.12.6129-6137.2002

Coppola G, Papurello D (2018) Biogas cleaning: activated carbon regeneration for $\mathrm{H} 2 \mathrm{~S}$ removal. Clean Technol 1:40-57. https://doi.org/10. 3390/cleantechnol1010004

Dinkel VG, Frechen FB, Dinkel AV, Smirnov YY, Kalyuzhnyi SV (2010) Kinetics of anaerobic biodegradation of glycerol by sulfatereducing bacteria. Appl Biochem Microbiol 46:712-718. https://doi. org/10.1134/S0003683810070069

El Bayoumy MA, Bewtra JK, Ali HI, Biswas N (1999) Sulfide production by sulfate reducing bacteria with lactate as feed in an upflow anaerobic fixed film reactor. Water Air Soil Pollut 112:67-84. https://doi.org/10.1023/A:1005016406707 
Habe H, Sato Y, Aoyagi T, Inaba T, Hori T, Hamai T, Hayashi K, Kobayashi M, Sakata T, Sato N (2020) Design, application, and microbiome of sulfate-reducing bioreactors for treatment of mining-influenced water. Appl Microbiol Biotechnol 104:68936903. https://doi.org/10.1007/s00253-020-10737-2

Habouzit F, Gévaudan G, Hamelin J, Steyer JP, Bernet N (2011) Influence of support material properties on the potential selection of Archaea during initial adhesion of a methanogenic consortium. Bioresour Technol 102:4054-4060. https://doi.org/10.1016/j. biortech.2010.12.023

Hadjiev D, Dimitrov D, Martinov M, Sire O (2007) Enhancement of the biofilm formation on polymeric supports by surface conditioning. Enzym Microb Technol 40:840-848. https://doi.org/10.1016/j. enzmictec.2006.06.022

Hausmann B, Knorr K-H, Schreck K, Tringe SG, Glavina Del Rio T, Loy A, Pester M (2016) Consortia of low-abundance bacteria drive sulfate reduction-dependent degradation of fermentation products in peat soil microcosms. ISME J 10:2365-2375. https://doi.org/10. 1038/ismej.2016.42

Huysman P, Van Meenen P, Van Assche P, Verstraete W (1983) Factors affecting the colonization of non porous and porous packing materials in model upflow methane reactors. Biotechnol Lett 5:643648. https://doi.org/10.1007/BF00130849

Kaksonen AH, Puhakka JA (2007) Sulfate reduction based bioprocesses for the treatment of acid mine drainage and the recovery of metals. Eng Life Sci 7:541-564. https://doi.org/10.1002/elsc.200720216

Kaksonen AH, Franzmann PD, Puhakka JA (2003) Performance and ethanol oxidation kinetics of a sulfate-reducing fluidized-bed reactor treating acidic metal-containing wastewater. Biodegradation 14: 207-217. https://doi.org/10.1023/A:1024262607099

Kaksonen AH, Plumb JJ, Robertson WJ, Riekkola-Vanhanen M, Franzmann PD, Puhakka JA (2006) The performance, kinetics and microbiology of sulfidogenic fluidized-bed treatment of acidic metal- and sulfate-containing wastewater. Hydrometallurgy 83: 204-213. https://doi.org/10.1016/j.hydromet.2006.03.025

Kim IH, Choi JH, Joo JO, Kim YK, Choi JW, Oh BK (2015) Development of a microbe-zeolite carrier for the effective elimination of heavy metals from seawater. J Microbiol Biotechnol 25: 1542-1546. https://doi.org/10.4014/jmb.1504.04067

Kleikemper J, Pelz O, Schroth MH, Zeyer J (2002) Sulfate-reducing bacterial community response to carbon source amendments in contaminated aquifer microcosms. FEMS Microbiol Ecol 42:109-118. https://doi.org/10.1111/j.1574-6941.2002.tb01000.x

Kolmert A, Johnson DB (2001) Remediation of acidic waste waters using immobilised, acidophilic sulfate-reducing bacteria. J Chem Technol Biotechnol 76:836-843. https://doi.org/10.1002/jctb.453

Koschorreck M, Herzsprung P, Wendt-Potthoff K, Lorke A, Geller W, Luther G, Elsner W, Müller M (2002) An in-lake reactor to treat an acidic lake: the effect of substrate overdosage. Mine Water Environ 21:137-149. https://doi.org/10.1007/s102300200034

Kremer DR, Hansen TA (1987) Glycerol and dihydroxyacetone dissimilation in Desulfovibrio strains. Arch Microbiol 147:249-256. https://doi.org/10.1007/BF00463484

Kubota M, Nakabayashi T, Matsumoto Y, Shiomi T, Yamada Y, Ino K, Yamanokuchi H, Matsui M, Tsunoda T, Mizukami F, Sakaguchi K (2008) Selective adsorption of bacterial cells onto zeolites. Colloids Surf B: Biointerfaces 64:88-97. https://doi.org/10.1016/j.colsurfb. 2008.01.012

Kuever J (2014) The family Desulfobacteraceae. In: The Prokaryotes: Deltaproteobacteria and Epsilonproteobacteria. Springer-Verlag, Berlin Heidelberg, pp 45-73

Liu W, Adanur S (2014) Desulfurization properties of activated carbon fibers. J Eng Fiber Fabr 9:70-75. https://doi.org/10.1177/ 155892501400900208

Lu J, Chen T, Wu J, Wilson PC, Hao X, Qian J (2011) Acid tolerance of an acid mine drainage bioremediation system based on biological sulfate reduction. Bioresour Technol 102:10401-10406. https://doi. org/10.1016/j.biortech.2011.09.046

Meier J, Piva A, Fortin D (2012) Enrichment of sulfate-reducing bacteria and resulting mineral formation in media mimicking pore water metal ion concentrations and $\mathrm{pH}$ conditions of acidic pit lakes. FEMS Microbiol Ecol 79:69-84. https://doi.org/10.1111/j.15746941.2011.01199.x

Montes-Morán MA, Suárez D, Menéndez JA, Fuente E (2004) On the nature of basic sites on carbon surfaces: an overview. Carbon 42 : 1219-1225. https://doi.org/10.1016/j.carbon.2004.01.023

Montoya L, Celis LB, Gallegos-García M, Razo-Flores E, Alpuche-Solís ÁG (2013) Consortium diversity of a sulfate-reducing biofilm developed at acidic $\mathrm{pH}$ influent conditions in a down-flow fluidized bed reactor. Eng Life Sci 13:302-311. https://doi.org/10.1002/elsc. 201200047

Moreno-Perlin T, Alpuche-Solís ÁG, Badano EI, Etchebehere C, Celis LB (2019) Toward a solution for acid mine drainage treatment: role of electron donors in sulfate reduction at low $\mathrm{pH}$. Geomicrobiol J 36: 837-846. https://doi.org/10.1080/01490451.2019.1636165

Nancucheo IN, Johnson DB (2012) Selective removal of transition metals from acidic mine waters by novel consortia of acidophilic sulfidogenic bacteria. Microb Biotechnol 5:34 44. https://doi.org/ 10.1111/j.1751-7915.2011.00285.x

Nancucheo I, Johnson B (2014) Removal of sulfate from extremely acidic mine waters using low $\mathrm{pH}$ sulfidogenic bioreactors. Hydrometallurgy 150:222-226. https://doi.org/10.1016/j. hydromet.2014.04.025

Nancucheo I, Bitencourt JAP, Sahoo PK, Alves JO, Siqueira J, Oliveira G (2017) Recent developments for remediating acidic mine waters using sulfidogenic bacteria. BioMed Res Int 2017. https://doi.org/ 10.1155/2017/7256582

Oksanen J, Blanchet FG, Friendly M, Kindt R, Legendre P, Mcglinn D, Minchin PR, O'hara RB, Simpson GL, Solymos P, Henry M, Stevens H, Szoecs E, Maintainer HW (2019) Package "vegan" Title Community Ecology Package

Oliveira R, Azeredo J, Teixeira P (2003) The importance of physicochemical properties in biofilm formation and activity. In: Wuertz S, Bishop PL, Wilderer PA (eds) Biofilms in wastewater treatment : an interdisciplinary approach. IWA Publishing, pp 211-231

Papirio S, Villa-Gomez DK, Esposito G, Pirozzi F, Lens PNL (2013) Acid mine drainage treatment in fluidized-bed bioreactors by sulfate-reducing bacteria: a critical review. Crit Rev Environ Sci Technol 43:2545-2580. https://doi.org/10.1080/10643389.2012. 694328

Pereira MA, Alves MM, Azeredo J, Mota M, Oliveira R (2000) Influence of physico-chemical properties of porous microcarriers on the adhesion of an anaerobic consortium. J Ind Microbiol Biotechnol 24: 181-186. https://doi.org/10.1038/sj.jim.2900799

Qatibi, AI, Bennisse R, Jana M, Garcia JL (1998) Anaerobic degradation of glycerol by Desulfovibrio fructosovorans and D. carbinolicus and evidence for glycerol-dependent utilization of 1,2-propanediol. Curr Microbiol 36:283-290. https://doi.org/10.1007/s002849900311

Quast C, Pruesse E, Yilmaz P, Gerken J, Schweer T, Yarza P, Peplies J, Glöckner FO (2013) The SILVA ribosomal RNA gene database project: improved data processing and web-based tools. Nucleic Acids Res 41:D590-D596. https://doi.org/10.1093/nar/gks1219

R Core Team and R Development Core Team. (2005) R: a language and environment for statistical computing

Ramiro-Garcia J, Hermes GDA, Giatsis C, Sipkema D, Zoetendal EG, Schaap PJ, Smidt H (2016) NG-Tax, a highly accurate and validated pipeline for analysis of $16 \mathrm{~S}$ rRNA amplicons from complex biomes. F1000Research 5:1791. https://doi.org/10.12688/f1000research. 9227.1

Reyes C, Schneider D, Thürmer A, Kulkarni A, Lipka M, Sztejrenszus SY, Böttcher ME, Daniel R, Friedrich MW, Th€ Urmer B A, B€ Ottcher C ME (2017) Potentially active iron, sulfur, and sulfate 
reducing bacteria in Skagerrak and Bothnian bay sediments. Geomicrobiol J 34:840-850. https://doi.org/10.1080/01490451. 2017.1281360

Rodriguez-Freire L, Moore SE, Sierra-Alvarez R, Root RA, Chorover J, Field JA (2016) Arsenic remediation by formation of arsenic sulfide minerals in a continuous anaerobic bioreactor. Biotechnol Bioeng 113:522-530. https://doi.org/10.1002/bit.25825

Sahinkaya E, Gunes FM, Ucar D, Kaksonen AH (2011) Sulfidogenic fluidized bed treatment of real acid mine drainage water. Bioresour Technol 102:683-689. https://doi.org/10.1016/j.biortech.2010.08. 042

Sánchez-Andrea I, Triana D, Sanz JL (2012) Bioremediation of acid mine drainage coupled with domestic wastewater treatment. Water Sci Technol 66(11):2425-2431. https://doi.org/10.2166/wst.2012.477

Sánchez-Andrea I, Stams AJM, Amils R, Sanz JL (2013) Enrichment and isolation of acidophilic sulfate-reducing bacteria from Tinto River sediments. Environ Microbiol Rep 5:672-678. https://doi.org/10. 1111/1758-2229.12066

Sánchez-Andrea I, Sanz JL, Bijmans MFM, Stams AJM (2014) Sulfate reduction at low $\mathrm{pH}$ to remediate acid mine drainage. J Hazard Mater 269:98-109. https://doi.org/10.1016/J.JHAZMAT.2013.12. 032

Santos AL, Johnson DB (2017) The effects of temperature and $\mathrm{pH}$ on the kinetics of an acidophilic sulfidogenic bioreactor and indigenous microbial communities. Hydrometallurgy 168:116-120. https:// doi.org/10.1016/j.hydromet.2016.07.018

Santos AL, Johnson DB (2018) Design and application of a low pH upflow biofilm sulfidogenic bioreactor for recovering transition metals from synthetic waste water at a Brazilian copper mine. Front Microbiol 9:2051. https://doi.org/10.3389/fmicb.2018.02051

Shan L, Zhang Z, Yu Y, Ambuchi JJ, Feng Y (2017) Performance of CSTR-EGSB-SBR system for treating sulfate-rich cellulosic ethanol wastewater and microbial community analysis. Environ Sci Pollut Res 24:14387-14395. https://doi.org/10.1007/s11356017-9022-5

Silva AJ, Hirasawa JS, Varesche MB, Foresti E, Zaiat M (2006) Evaluation of support materials for the immobilization of sulfatereducing bacteria and methanogenic archaea. Anaerobe 12:93-98. https://doi.org/10.1016/J.ANAEROBE.2005.12.003

Stams AJM, Van Dijk JB, Dijkema C, Plugge CM (1993) Growth of syntrophic propionate-oxidizing bacteria with fumarate in the absence of methanogenic bacteria. Appl Environ Microbiol 59:11141119. https://doi.org/10.1128/aem.59.4.1114-1119.1993

Tran H-L, Kuo M-S, Yang W-D, Huang Y-C (2016) Hydrogen sulfide adsorption by thermally treated cobalt (II)-exchanged $\mathrm{NaX}$ zeolite: 275-286. https://doi.org/10.1177/0263617416648964

Vuillemin A, Horn F, Friese A, Winkel M, Alawi M, Wagner D, Henny C, Orsi WD, Crowe SA, Kallmeyer J (2018) Metabolic potential of microbial communities from ferruginous sediments. Environ Microbiol 20:4297-4313. https://doi.org/10.1111/1462-2920.14343

Wang S, Peng Y (2010) Natural zeolites as effective adsorbents in water and wastewater treatment. Chem Eng J 156:11-24. https://doi.org/ 10.1016/j.cej.2009.10.029

Watanabe M, Kojima H, Fukui M (2018) Review of Desulfotomaculum species and proposal of the genera Desulfallas gen. nov., Desulfofundulus gen. nov., Desulfofarcimen gen. nov. and Desulfohalotomaculum gen. nov. Int J Syst Evol Microbiol 68: 2891-2899. https://doi.org/10.1099/ijsem.0.002915

Publisher's note Springer Nature remains neutral with regard to jurisdictional claims in published maps and institutional affiliations. 